\title{
Renewable Energy Technologies as Distribution Generation and its effect on Electrical Distribution System in a Semi Desert Area
}

\author{
Abdalfettah Asharaa ${ }^{1,2,3,6}$, Yousef Dama ${ }^{4}$, Mohammad Al-Jaafreh ${ }^{1}$, Majid Salim Ali Alkhambashi ${ }^{1}$, Ali \\ Almagouri ${ }^{7}$, Issa Elfergani ${ }^{1}$, Embarak M Ibrahim Elfoghi ${ }^{6}$, Adnan Asharaa ${ }^{3,7}$, Buhari Mohammed ${ }^{1}$, Ali A. S. \\ Alabdullah $^{1,5}$, Widad Mshwat ${ }^{1}$, Rana Zubo $^{1,8}$, Abdalla Fadel ${ }^{2}$, Raed Abd-Alhameed ${ }^{1}$ \\ \{Asharaa12345@gmail.com, A.S.M.Asharaa@bradford.ac.uk\}
}

\author{
University of Bradford, Bradford, West Yorkshire, Bradford, United Kingdom ${ }^{1}$ \\ School of Engineering and Applied Science, The Libyan Academy, Libya, Tripoli ${ }^{2}$ \\ College of Electrical Engineering, Bani Walid University, Bani Walid, Libya ${ }^{3}$ \\ Faculty of Engineering, An-Najah National University, Palestine ${ }^{4}$ \\ College of Electronics Engineering, Ninevah University, Iraq ${ }^{5}$ \\ College of Electronic Technology Bani Walid Libya ${ }^{6}$ \\ The University of Tripoli, Libya, Tripoli ${ }^{7}$ \\ Northern Technical University,Iraq ${ }^{8}$
}

\begin{abstract}
This paper focuses on renewable energy generated generation (DG) systems that will satisfy the operational requirement in different cases. The global need for a sustainable energy system is becoming very important over the next few years due to the recent attention on conventional energy resources such as fossil fuels which have effects on the environment. The renewable energy technologies such as solar energy systems are becoming more critical energy technology of the generation system. However, selecting optimal sites for DG systems depends on the local conditions and potential of renewable energy. In this work, a semi-desert area network of Libyan electrical distribution systems has been chosen as a case study. The objectives of this work are to observe the effects of DG systems in an electrical distribution system and also to present its different performance levels. Furthermore, this paper presents the implementation of a Newton Raphson method using NEPLAN software to analyze the transition and the use of sub-transmission networks, interconnecting the DG units for a semi-desert area in Libya. The simulation results are analyzed and discussed to make a suggestion for adapting this method in using the sub-transmission networks to interconnect the DG systems.
\end{abstract}

Keywords: Renewable Energy Systems (RES), Distributed Generation (DG), Electrical Distribution System, Libya, Semi Desert Area, Solar Energy, Photovoltaic (PV).

\section{Introduction}

Nowadays, the evolution of the electric power industry undergoes indispensable changes and challenges throughout the world. Significant carbon emission increase in the atmosphere due to high demand of generated energy by fossil fuel resources (e.g. natural gas and crude oil) which cause environmental concern such as the global warming is resulting to the significant increase of the carbon emission to the atmosphere. According to prediction, the energy consumption will increase throughout the world rising to 37 kilo-terawatt hours in 2030 [1]. As a result, many countries have accepted based on the Kyoto protocol to reduce 50\% of the greenhouse emission by 2050 . Furthermore, high world economic development and exponential population growth cause a high increase in demand for energy which leads to the shortage of energy and increase the greenhouse gas emission in the atmosphere [2]. Achieving solution for the mentioned problems that presently the energy sector over the world needs long term planning actions for shifting the power generation sector and electric power system for more sustainable system by increasing the generation from renewable energy sources (RESs) such as photovoltaic (PV) systems and wind in the form of distributed generations (DGs) [3]. Distributed generation (DG) is an important system in the electric power system infrastructure and market. It is an electrical power source that is linked right to the distribution network or customer on-site. Also according to [4], DG is simply defined as a small-scale electricity generation. Furthermore, different agencies define the DG system differently. But according to the International energy agency (IEA) distributed generation is a generation plant that supplies power to customers' premises or to the grid at the distribution level [5]. International council on the large electric system (ICLE) defines DG as an electric power generation that is less than $100 \mathrm{MW}$ in which the system is not planned to be centralled or dispatched, but is simply linked to the distribution network or customers on-site. However, the electric power research institute (EPRI) looked at it the other way round as electric power generation ranging from few kilowatts to $50 \mathrm{MW}$ [6]. 
There are several types of DG systems available in the market such as photovoltaic, wind turbines, internal combustion engines, combustion turbines, microturbines, and fuel cells, among others [7]. 
Distributed generation (DG) may encounter technical and safety problems during integration into other distribution networks. The system is sensitive to increase fault currents, cause voltage oscillations, interfere with voltage-control processes, diminish or increase losses depending on the site location [8]. However, according to [9], there are limitations in determining the DG location. Studies have shown base on the existing index that DG can be more useful for the distribution networks. DG can also be allocated in the best optimum way to reduce power losses, improve reliability, power quality and the voltage profile the chances of connecting more distribution networks will increase [8]. As previously mentioned, the main limitations of DG during integration are the operational constraints such as thermal constraints and voltage constraints. The conventional "fit-and-forget" principle only accepts DG where there is no constraint violation under the worst-case condition which causes limitation in connecting the DG to the network as they are no longer passive[10]. The smart grid technology such as active network management (ANM) scheme can be developed to explore DG benefits which can address the weaknesses caused by the "fit-andforget" principle. It is important to reshape the operation and planning strategies of the electricity distribution system to benefit from the potentials of the DG system. It has been indicated, in the future that a high increase in customer demands led may allow ANM to effectively and efficiently connect small and medium scale electric power sources. The distributed generation (DG) is commonly used as back-up power to improve network reliability. It can also be a means of put back investment in transmission and distribution networks, nullifies network charges, decreases line losses, delays construction of extensive generation facilities, replaces costly grid-supplied power, makes provision for alternative sources of supply in markets and provides environmental benefits [11] [12].

In the Distribution Generation (DG) research, several critical features are left unsearched and unexplored which these areas require more specific study, even though, the DG system is presently assumed to be well researched. However, in this research, it was believed to be worthy to widely investigate the electrical distribution system in order to identify and discuss its reactivities. It is believed that this could result in achieving an optimum electrical distribution system. In this research, analysis and discussion of sub-transmission networks with the interconnection of DG units for a semi-desert area in Libya will be considered.

\section{Case study}

The main idea behind this study is to use a renewable energy source, especially photovoltaic as the distribution generation (DG) in the southern area of Libya. The south area of Libya is a semi-desert area and the irradiation was in large where Samno or Samnu network is located. To show the effects and the impacts of applying DG systems to the semi-desert area of southern Libya, Samno 220/66 KV substation is considered. The DG units are also considered to be a renewable energy source such that solar radiation is very high. The sub-station of Samno (220/66) $\mathrm{KV}$ is fed from the Libyan local grid and suffers low voltage profile during the peak period and high radiation of reactive power as a result of high reactive loads in the area. Figure 1 shows the 66kv network that feeds from $220 \mathrm{KV}$ bus through three (220/66) KV transformers of 63 MVA size each. The main busbar of Samno 66 KV feeds 10 busbars through the $66 \mathrm{KV}$ transmission system, as indicated on the network design. This network will be analyzed using power flowing (PF) and optimal power flow program (OPF) using different operation scenarios at peak loading time and at PVDG penetration ratios. Finally, in this work, the case study will be analyzed, simulated and discusse the network in normal operation, optimal operation, and Samno optimal isolated. Then Irradiation Curve with the daily load curve will also be presented in detail. Samno location, Samno is a town located in a Saharan oasis, where the Tamanhint Airport is nearest Libyan airport. It is located about $800 \mathrm{~km}$ southwest of Tripoli in the desert region, its geographical coordinates are: 27 16' 00" latitude north and 14 54' 00" longitude east. Note, some online websites translate Samno world from Arabic to other languages as Samnu, which ends by U latter. And please keep in mind that the busbars are with red color instead of green color that will be shown in the figures mean that the voltages at the load end are still low.

\subsection{Normal Operation:}

In this case, the network is operating as a steady-state, and there is a Ten Distribution Substation connecting to the Samno network 220KV. These substations are (Samno, Temenhent A, Temenhent B, Temenhent City, Alshareet, New Sabha, Samno City, Aledaha, North Sabha 1, Alhejara), as shown in Figure 1 below. 


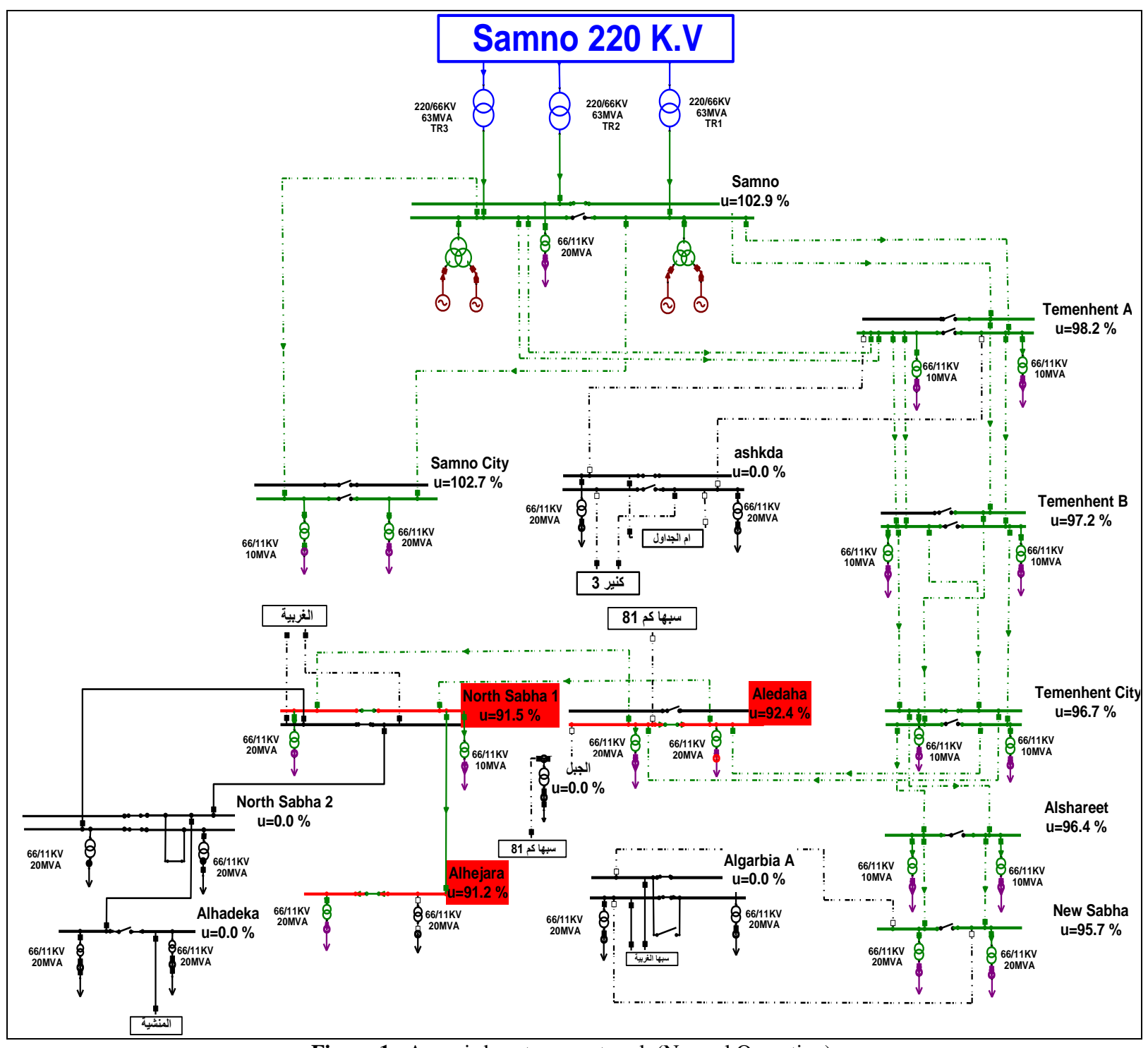

Figure 1: A semi-desert area network (Normal Operation).

The total load for this network is $\left(\mathrm{P}_{\text {load }}=76.6 \mathrm{MW}\right)$, and power losses are $\left(\mathrm{P}_{\text {Loss }}=4.085 \mathrm{MW}\right)$, and the power generation is $\left(\mathrm{P}_{\mathrm{G}}=80.637 \mathrm{MW}\right)$. And there are three distribution substations (See busbars are with red color) have voltages less than 95\%, at (Aledaha, North Sabha 1, Alhejara). As shown in Table 1 and Figure 2.

Table 1: Voltage value in distribution substations

\begin{tabular}{lc}
\hline Locations & V \% \\
\hline Samno & 103 \\
Temenhent A & 98.2 \\
Temenhent B & 97.2 \\
Temenhent City & 96.7 \\
Alshareet & 96.4 \\
New Sabha & 95.7 \\
Samno city & 103 \\
Aledaha & 92.4 \\
North Sabha 1 & 91.5 \\
Alhejara & 91.2 \\
& \\
\hline
\end{tabular}

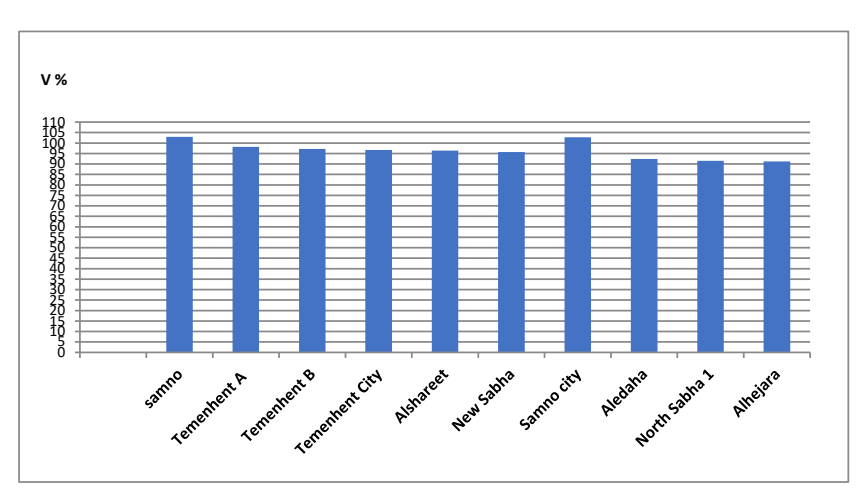

Figure 2: Three distribution substations voltages less than $95 \%$ 


\subsection{Optimal Operation}

In this case, there is a distribution generation connecting to the network, and we should find the best location at the distribution substations when the losses is minimum, and the voltages at all buss are acceptable $( \pm 5 \%)$, after many steps, the best location is founded at (North Sabha 1 ) as shown in figure 3 , and the capacity of the $\mathrm{DG}$ is $(\mathrm{P}=$ $22 \mathrm{MW})$ and the reactive power needed is $(\mathrm{Q}=33.84 \mathrm{MVAR})$.

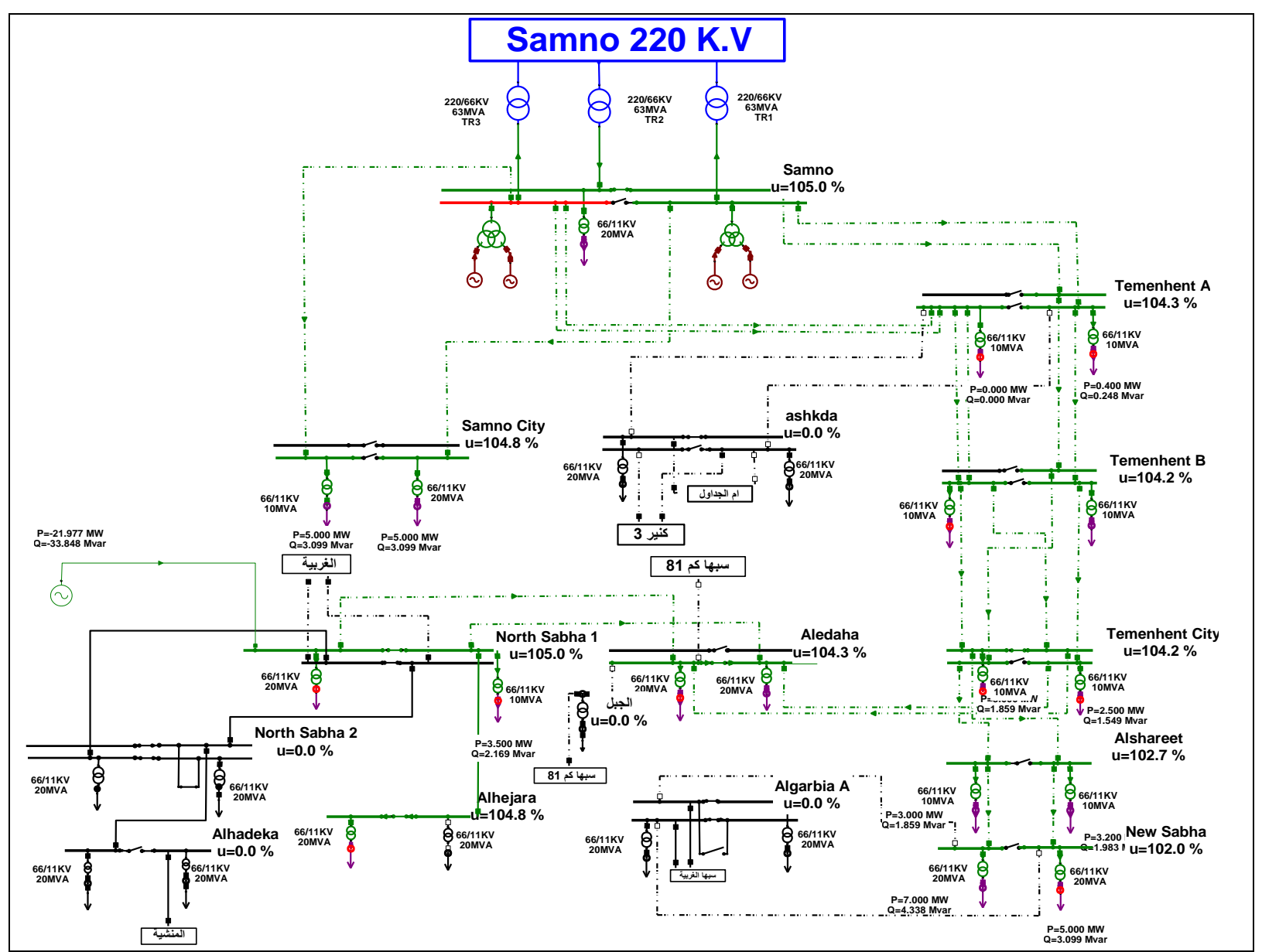

Figure 3: Optimal operation case (DG connected to the network at North Sabha 1)

Figure 4 illustrates that the power losses result is reduced from (P losses $=4.085 \mathrm{M} . \mathrm{W})$ to $(\mathrm{P}$ losses $=1.376 \mathrm{MW})$. And also the magnitude of the voltages has been improved as shown in Table 2 and figure 5 below.

Table 2: Voltage value in distribution substations

\begin{tabular}{lc}
\hline Locations & V \% \\
\hline Samno & 105 \\
Temenhent A & 104.3 \\
Temenhent B & 104.2 \\
Temenhent City & 104.2 \\
Alshareet & 102.7 \\
New Sabha & 102 \\
Samno city & 104.8 \\
Aledaha & 104.3 \\
North Sabha 1 & 105 \\
Alhejara & 104.8 \\
& \\
\hline
\end{tabular}

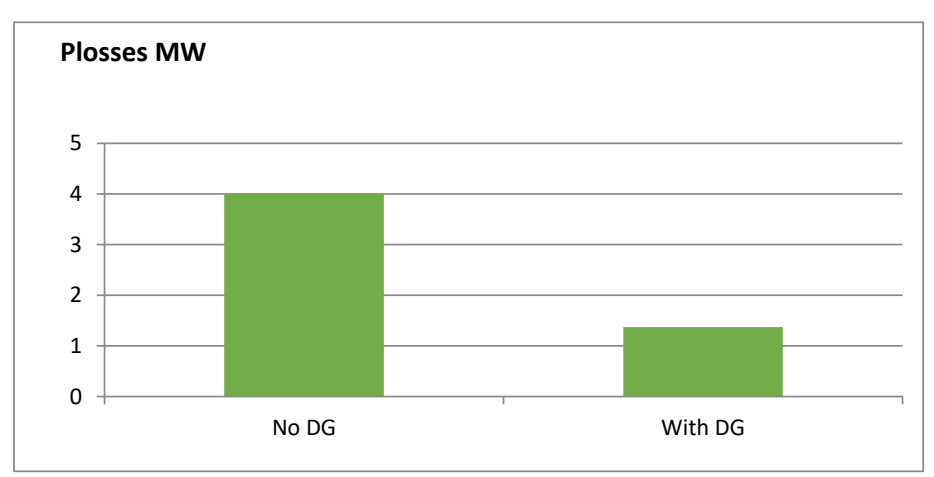

Figure 4: The power losses result. 


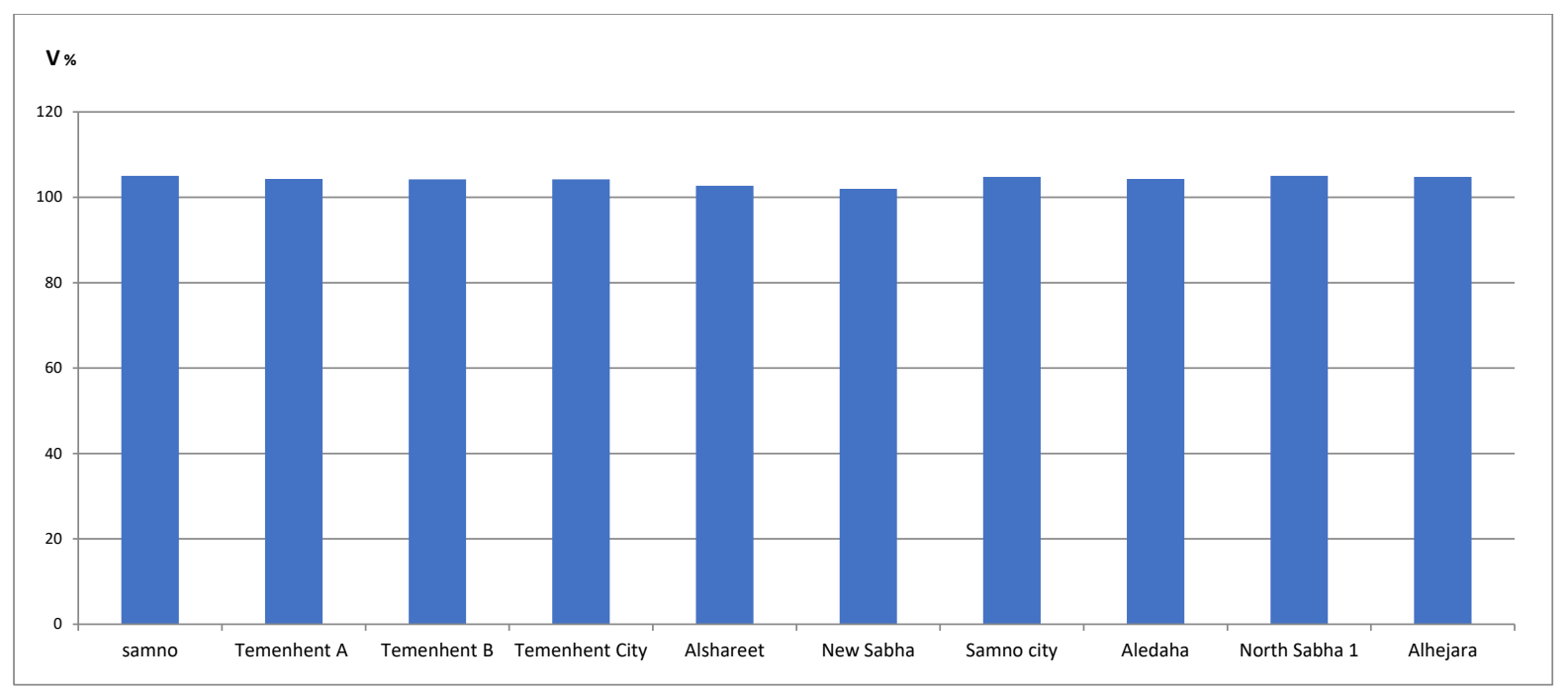

Figure 5: Distribution substations voltages more than $95 \%$

\subsection{Samno Optimal Isolated:}

This case explains how to evaluate the capacity of the DG, and its position when the power losses in the network are minimum, and the voltages at the buss are within limits $( \pm 5 \%)$. From the rated value, as shown in figure 6 . After several simulations, the rating of the distributed generation is founded as $[\mathrm{P}=100 \mathrm{MW}, \mathrm{Q}=85 \mathrm{Mvar}]$. And the sitting of this D.G at North Sabha 2. Therefore, the power losses in the network are reduced to 3.897MW.

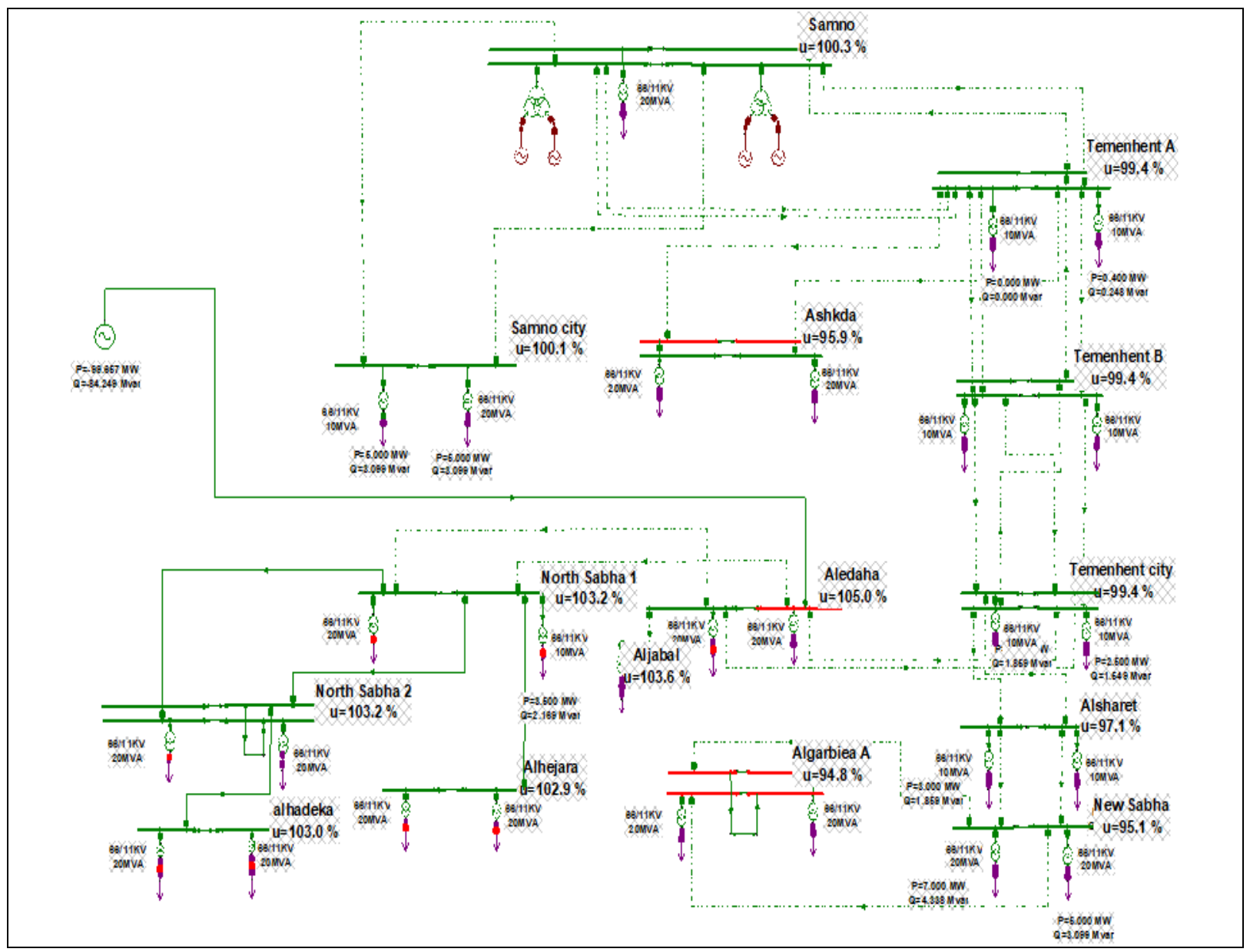

Figure 6: Samno Optimal Isolated Network 
The power losses in the network are reduced from [17.68 MW to 3.897MW] after DG connected. see the next Table 3 and figure 7.

Table 3: Power losses

\begin{tabular}{lc}
\hline Case & P $_{\text {losses }}$ MW \\
\hline No DG & 17.68 .3 \\
With DG & 3.897 \\
\end{tabular}

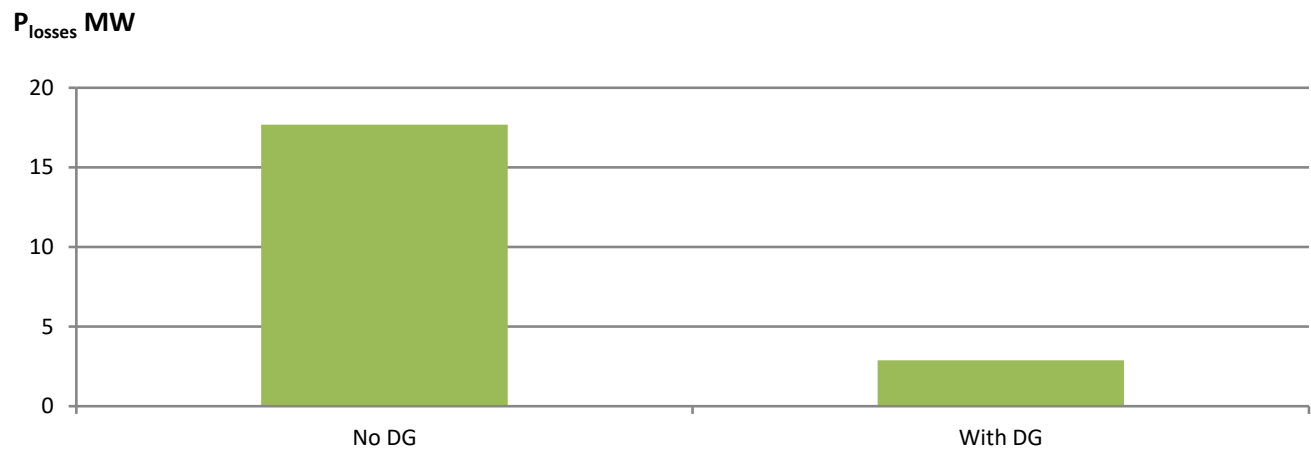

Figure 7: Power losses

The voltages magnitude at buss were improved when connecting DG. from the results, as shown in Table 4 and Figure 8 .

Table 4: Voltage in distribution substations

\begin{tabular}{lc}
\hline Locations & V \% \\
\hline Samno & 100.3 \\
Temenhent A & 99.4 \\
Temenhent B & 99.4 \\
Temenhent City & 99.4 \\
Alshareet & 97.1 \\
New Sabha & 95.1 \\
Samno city & 100.1 \\
Aledaha & 105 \\
North Sabha 1 & 103.2 \\
Alhejara & 102.9 \\
Ashkda & 95.9 \\
Algarbiea A & 94.8 \\
Aljabal & 103.6 \\
North Sabha 2 & 103.2 \\
Alhadeka & 103 \\
& \\
\hline
\end{tabular}

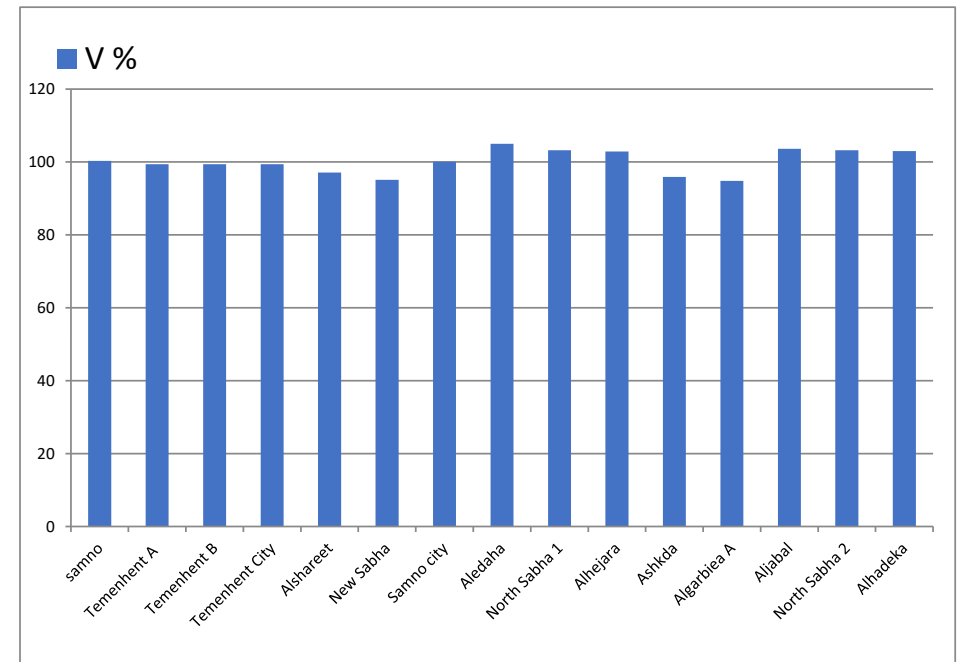

Figure 8: all distribution substations voltages appr. up 95\%

\section{Irradiation Curve:}

As a known, the photovoltaic as DG is depending on the irradiation, so when irradiation abounds, there is a power, when NO irradiation, there is NO power. And the global radiation on a horizontal surface is shown in table 5, and these measurements are obtained from the Energy Research Center (ERC). And Figure 9 shows the daily irradiation-curve for a summer day. 
Table 5: The Global Irradiation $\left(\mathrm{W} / \mathrm{m}^{2}\right)$ in 24 hours

\begin{tabular}{llll}
\hline Time(hours) & Radiation $\left(\mathbf{W} / \mathbf{m}^{\mathbf{2}}\right)$ & Time $($ hours $)$ & Radiation $\left(\mathbf{W} / \mathbf{m}^{\mathbf{2}}\right)$ \\
$\mathbf{1}$ & 0 & 13 & 990 \\
$\mathbf{2}$ & 0 & 14 & 917 \\
$\mathbf{3}$ & 0 & 15 & 780 \\
$\mathbf{4}$ & 0 & 16 & 585 \\
$\mathbf{5}$ & 30 & 17 & 375 \\
$\mathbf{6}$ & 140 & 18 & 154 \\
$\mathbf{7}$ & 343 & 19 & 20 \\
$\mathbf{8}$ & 532 & 20 & 0 \\
$\mathbf{9}$ & 747 & 21 & 0 \\
$\mathbf{1 0}$ & 910 & 22 & 0 \\
$\mathbf{1 1}$ & 1019 & 23 & 0 \\
$\mathbf{1 2}$ & 1062 & 24 & 0 \\
\hline
\end{tabular}

\section{(Radiation $\left(\mathrm{W} / \mathrm{m}^{2}\right)$}

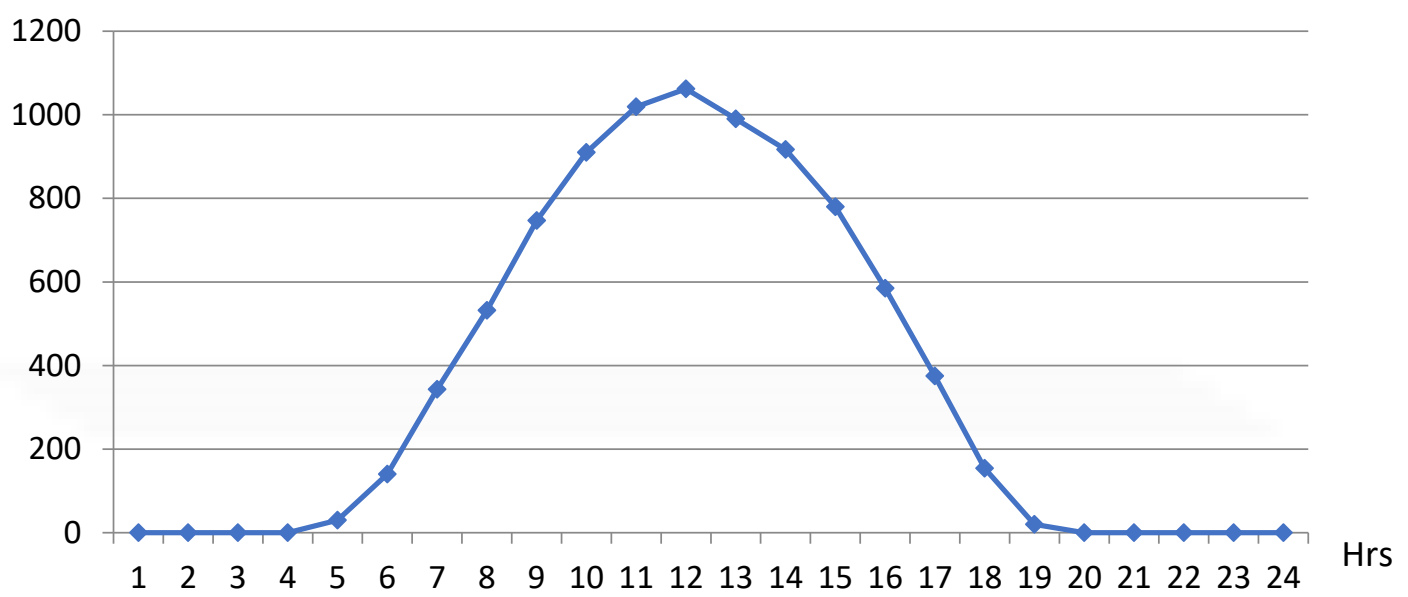

Figure 9: The daily irradiation-curve for a summer day

\section{Operating the network depends on the daily load curve:}

From the date was taken from the General Electricity Company of Libya (GECOL), the daily load curve starts growing at the morning, after sunrise when the irradiation is a pounded, and when plotted the daily load curve data, we noted the daily load curve is matched the irradiation curve, this means that the maximum load occurred when there are irradiation. Table 6 explains the daily load curve. 
Table 6: The daily load curve

\begin{tabular}{lcc}
\hline & Real & Approximated \\
$\mathbf{2}$ & 65 & 65 \\
$\mathbf{3}$ & 56 & 56 \\
$\mathbf{4}$ & 56 & 56 \\
$\mathbf{5}$ & 56 & 56 \\
$\mathbf{6}$ & 56 & 56 \\
$\mathbf{7}$ & 56 & 56 \\
$\mathbf{8}$ & 56 & 56 \\
$\mathbf{9}$ & 56 & 56 \\
$\mathbf{1 0}$ & 56 & 69 \\
$\mathbf{1 1}$ & 78 & 82 \\
$\mathbf{1 2}$ & 88.5 & 92 \\
$\mathbf{1 3}$ & 97 & 102 \\
$\mathbf{1 4}$ & 106 & 112 \\
$\mathbf{1 5}$ & 112.1 & 122 \\
$\mathbf{1 6}$ & 115 & 132 \\
$\mathbf{1 7}$ & 118 & 142 \\
$\mathbf{1 8}$ & 132.7 & 142 \\
$\mathbf{1 9}$ & 132.7 & 142 \\
$\mathbf{2 0}$ & 121 & 129 \\
$\mathbf{2 1}$ & 103 & 116 \\
$\mathbf{2 2}$ & 94 & 103 \\
$\mathbf{2 3}$ & 80 & 90 \\
$\mathbf{2 4}$ & 74 & 77 \\
\hline
\end{tabular}

The daily load curve can be approximated to geometrical figures because it is easy to calculate the area under the curve . as shown in figure 10.

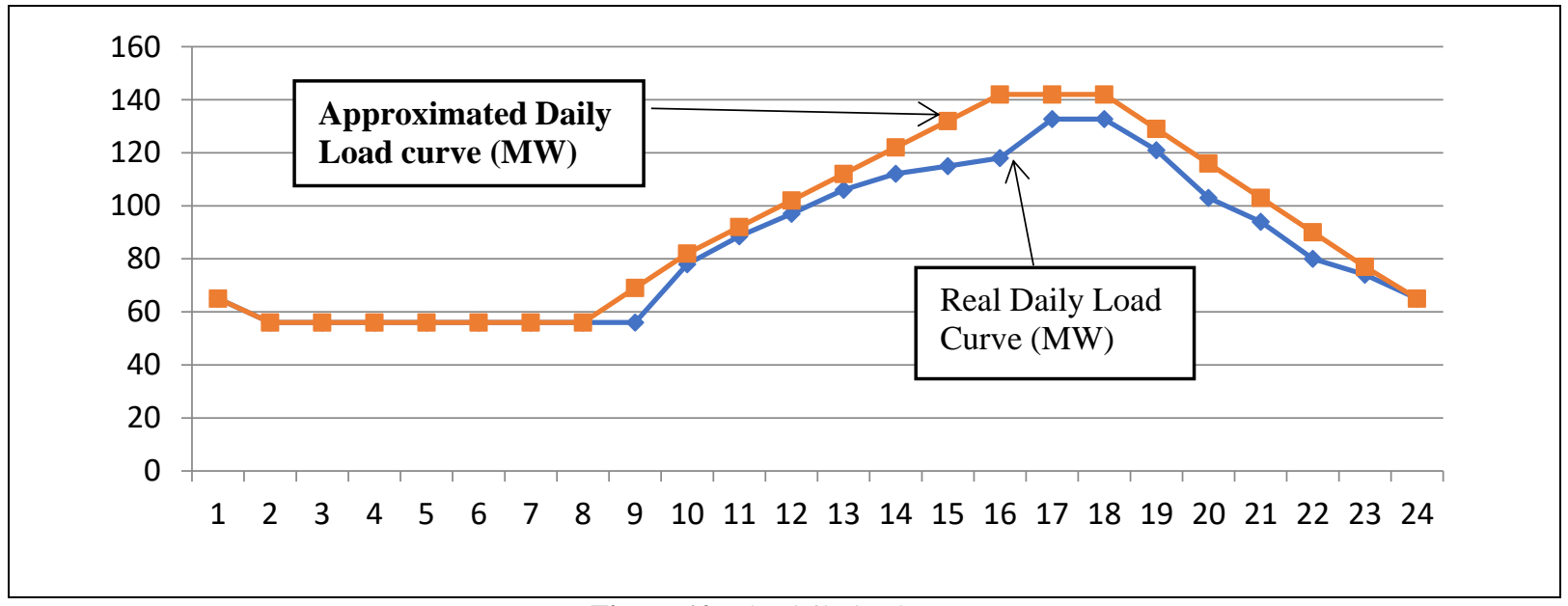

Figure 10: The daily load curve

The area under the curve represents the energy that consumed in One day ( 24 hours). From the figure, we note the base load is $56 \mathrm{MW}$. so the assumption in this case, is the baseload is feeding from the generators at Samno $(4 * 20 \mathrm{MW}=80 \mathrm{MW})$, and the other power is feeding on photovoltaic PV and the batteries E.S.S (Energy Storage System).

If the Network operating depending on a daily load curve, the size of PV is equal ( $\mathrm{PDG}=142-56=86 \mathrm{MW}$ ). From the approximate daily load curve, see figure 11, we can compute the rating of the batteries that needed for this case. 


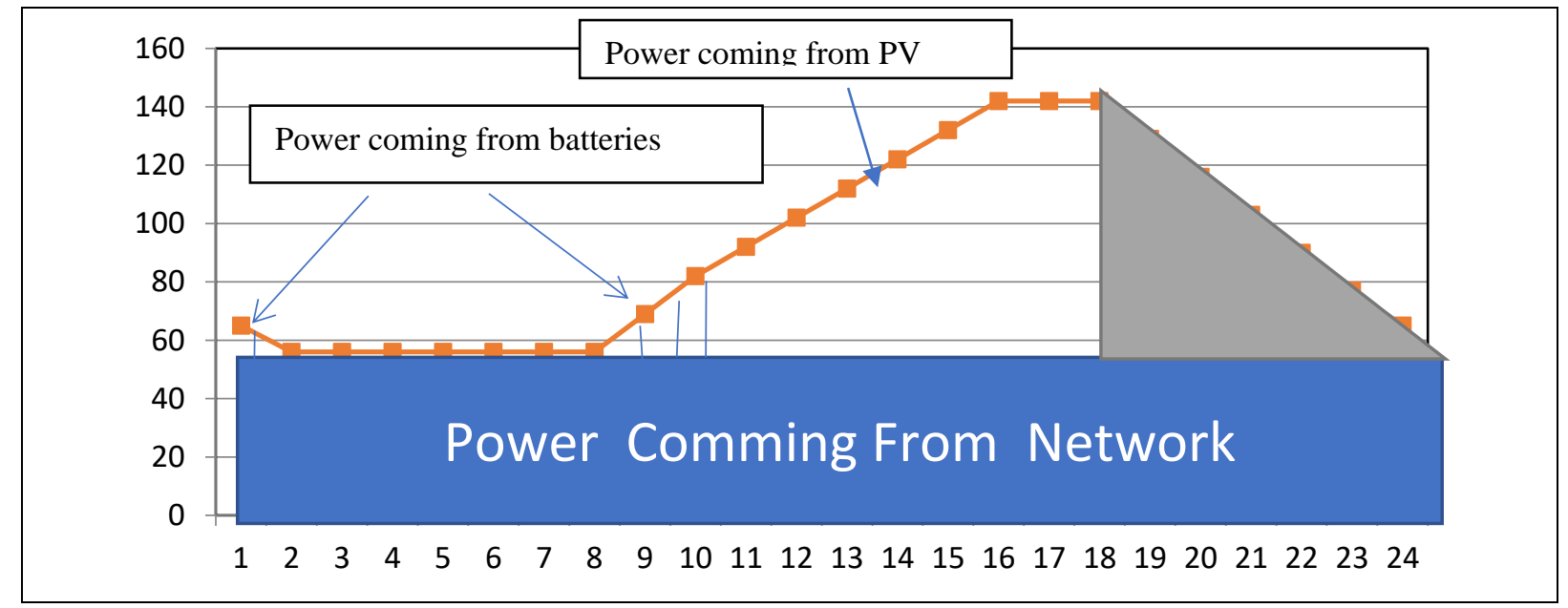

Figure 11: Approximate daily load curve

Batteries or charging system has been analyzed and calculated to be applied at the morning time of the day ( 1 to $2 \& 8$ to 10) as illustrated in the above figure. Also, the batteries system will be used at the evening time (18 to 24). The rating of the batteries is:

1) From (1am-2am) :

$\mathrm{A}=0.5 * 1 \mathrm{~h} *(65-56) \mathrm{MW}=4.5 \mathrm{MWh}$.

2) From (8am-10am) :

$\mathrm{A}=0.5 * 2 \mathrm{~h} *(82-56) \mathrm{MW}=\mathbf{2 6} \mathrm{MWh}$.

3) From ( $18-24)$ or (6pm -12am):

$\mathrm{A}=0.5 * 6 \mathrm{~h} *(142-56) \mathrm{MW}=\mathbf{2 5 8}$ MWh.

Total rating of Batteries $=\mathbf{2 8 8 . 5}$ MWh.

300MWh.

The power needed for charging is: $(300 \mathrm{MWh} / \mathbf{2 4 h})=\mathbf{1 2 . 5} \mathrm{MW}$.

The batteries can be charging from the generators at Samno because there is access power $(\mathbf{8 0}>\mathbf{5 6}+\mathbf{1 2 . 5}) \mathbf{M W}$.

Figure 12 shows the Samno network isolated from the Libyan network.

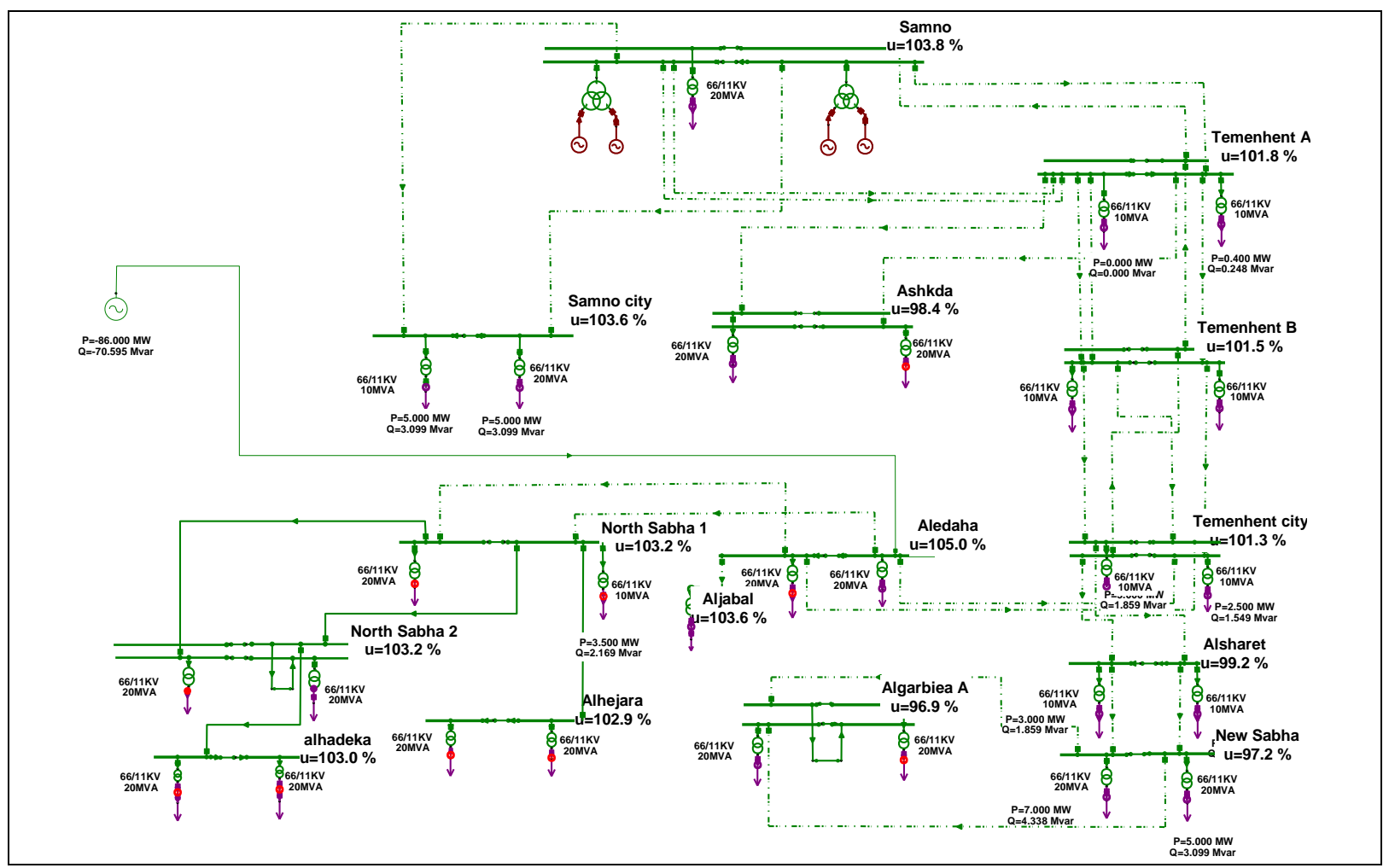

Figure 12: Samno network isolated from the Libyan network. 
From figure 12, the voltages are within limits, and the losses are decreased to ( $\mathbf{3 . 3 9 5} \mathbf{M W})$. Table 7 and figure 13 show the voltages at buss in the network, which demonstrates very good results (up 95\%)

Table 7: Voltage values at buss in the network

\begin{tabular}{ll}
\hline Locations & V \% \\
samno & 103.8 \\
Temenhent A & 101.8 \\
Temenhent B & 101.5 \\
Temenhent City & 101.3 \\
Alshareet & 99.2 \\
New Sabha & 97.2 \\
Samno city & 103.6 \\
Aledaha & 105 \\
North Sabha 1 & 103.2 \\
Alhejara & 102.9 \\
Ashkda & 98.4 \\
Algarbiea A & 96.9 \\
Aljabal & 103.6 \\
North Sabha 2 & 103.2 \\
\hline
\end{tabular}

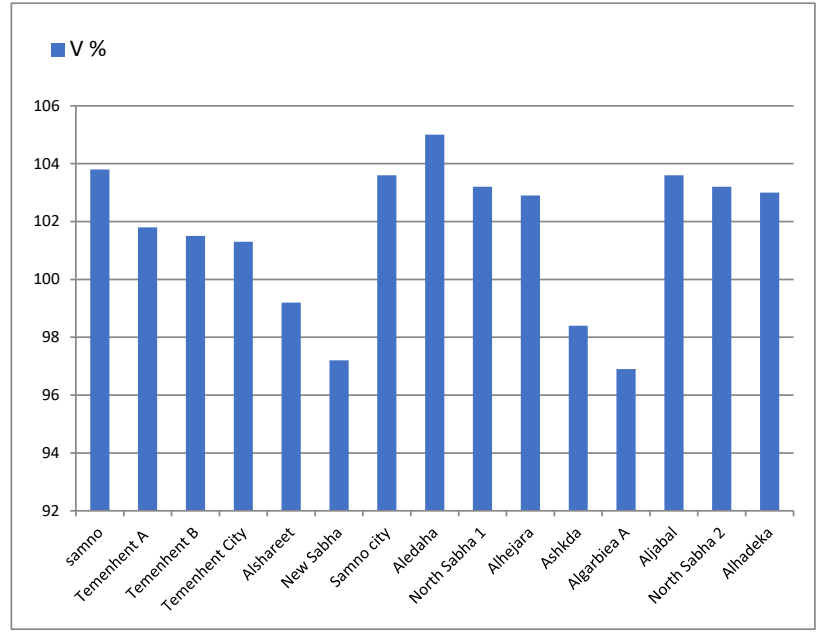

Figure 13: Voltage values at buss in the network.

\section{Operating PV system with $100 \%$ PV penetration:}

In this case, the magnitude of PV and STATCOM is ( $\mathrm{P}=86 \mathrm{MW} \& \mathrm{Q}=70.6 \mathrm{MVAR})$, As shown in figure 14.

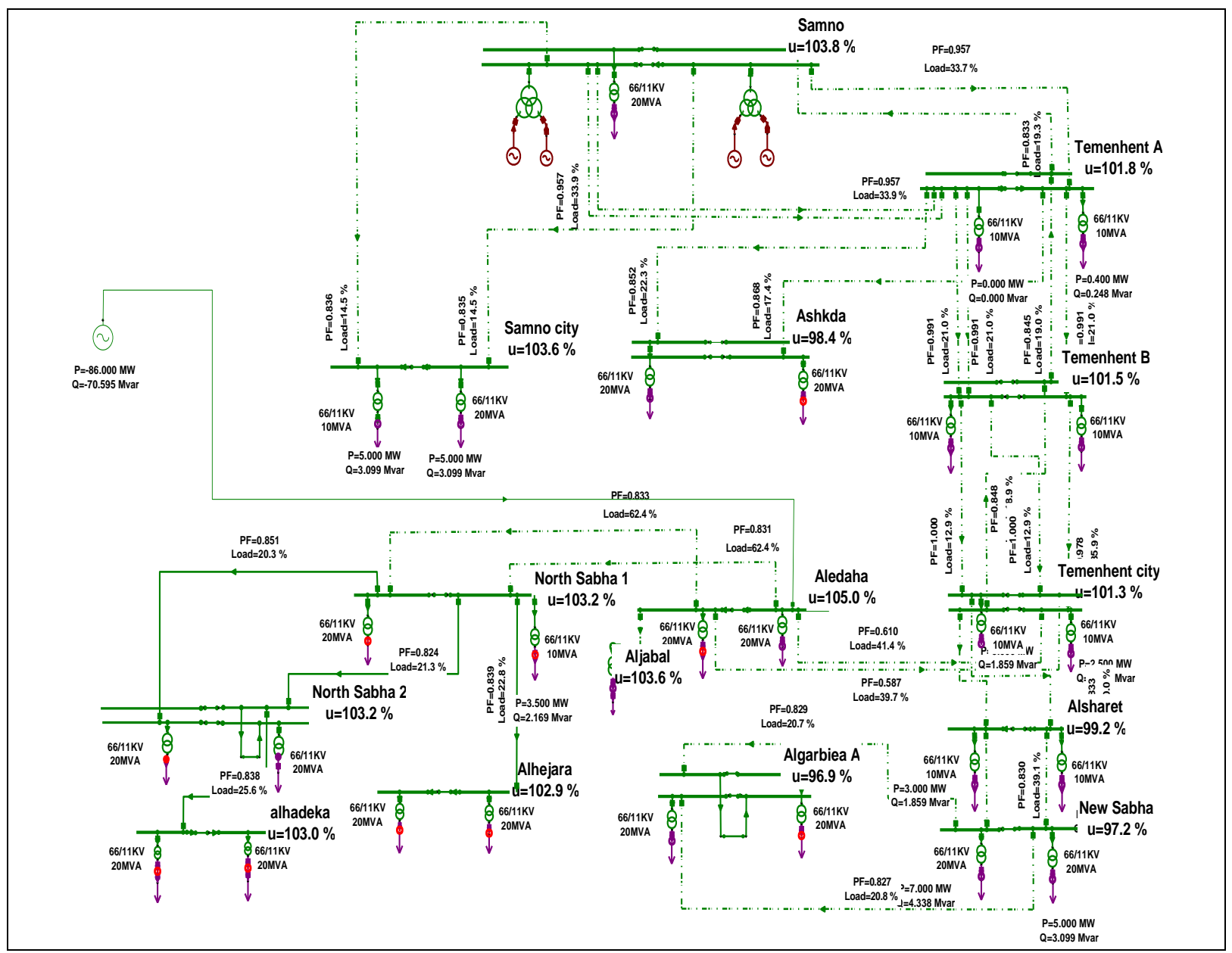

Figure 14: Operating PV system with $100 \%$ penetration. 
Table 8: Operating PV system with 100\% PV pentration

\begin{tabular}{ccccc}
\hline PV \% penetration & P (MW) & Q (MVAR) & Network losses (MW) & Voltage range \% \\
$100 \%$ penetration & 86 & 70.6 & 3.359 & $96.9-105$ \\
\hline
\end{tabular}

Last but not least, it is clear that the losses in the network as shown from the obtained results in table 8 have analysed while the of PV penetration has been operated. Also, the magnitude values of the voltage have improved up $95 \%$ as the percentage of PV penetration increased. Furthermore, P \& Q values at the operating PV system with $100 \%$ PV penetration illustrated. And network losses are explained in figure and Taple (MW). Lastly, maximum and minimum voltage values at the operating PV system with PV penetration demonstrate very good results up $95 \%$ as can be seen in figure 14 and Table 8 .

Finally, the Samno network with PVDG was simulated and performed well, proving that it can be used for improving the semi-desert area network, which was the main objective of this research. The final results were analysed and figured out with a very good performance after DG connected. Summing up the results, it can be concluded that The Samno network with PVDG has high-performance results; maximum and minimum voltage values at the operating PV system with PV penetration demonstrated a very good results upper 95\%. Also, the power losses in the network are reduced from [17.68 MW to 4MW] after DG connected.

\section{Conclusion}

This work demonstrated an innovative design and modeling of the semi-desert area network that is capable of achieving minimum power losses characteristics in different operating case. The aimed design of the PVDG for the semi-desert area has been successfully achieved by using NEPLAN software. The PVDG was presented and simulated with the help of using Newton Raphson beside NEPLAN software; this paper has clearly shown that various simulations and tests were conducted on the PVDG network. At the beginning of the chapter, the simulation and its results as normal operation networks were tested. Then, the optimal operation was analyzed from the simulation. Last but not least, the Samno isolated network was simulated, and its results explained. Finally, the optimal Samno network isolated was clearly defined. So, they supported the idea that required to a designer for confirming that improving the network by connecting a renewable energy resource as DG has been successfully achieved.

\section{Acknowledgements}

The Authors would like to take this opportunity to thank everybody who has helped me in one way or another during the preparation of this work. We could not have written this manuscript without the continuing confidence and support of Professor Abdalla Idris Fadel and Professor Raed Abd-Alhameed. Thank you for your help and guidance throughout the project, for seeing the potential in me all those months and giving me opportunities that developed this paper for what it is now. Many thanks are also extended to all employees in the General Electric Company of Libya GECOL.

\section{References}

[1] T. Shlebik, A. Fadel, M. Mhereeg, and M. Shlebik, "The development of a simulation-based smart grid communication management system using MATLAB," Int. Conf. Green Energy Convers. Syst. GECS $2017,2017$.

[2] M. A. A. Al-Jaafreh and G. Mokryani, "Planning and operation of LV distribution networks: a comprehensive review," IET Energy Syst. Integr., vol. 1, no. 3, pp. 133-146, 2019.

[3] C. Wang, S. Lei, P. Ju, C. Chen, C. Peng, and Y. Hou, "MDP-based Distribution Network Reconfiguration with Renewable Distributed Generation: An Approximate Dynamic Programming Approach," IEEE Trans. Smart Grid, vol. PP, no. c, pp. 1-1, 2020.

[4] P. A. Owusu and S. Asumadu-Sarkodie, "A review of renewable energy sources, sustainability issues and climate change mitigation," Cogent Eng., vol. 3, no. 1, 2016.

[5] E. Algadhi, A. Almraid and A. Asharaa "Comparative study for optimal re - planning of Libyan western boarder $30 \mathrm{~K}$. V system using the conventional methods and distri- bution generation penetration method," no. March, pp. 3-7, 2018.

[6] P. Kaur, S. Kaur, and R. Khanna, "Optimal placement and sizing of DG comparison of different techniques of DG placement," 1st IEEE Int. Conf. Power Electron. Intell. Control Energy Syst. ICPEICES 2016, pp. 1-4, 2017. 
[7] S. Nawaz, A. K. Bansal, and M. P. Sharma, "A novel DG allocation method for power loss reduction in radial distribution system," 2016 IEEE 7th Power India Int. Conf. PIICON 2016, 2017.

[8] M. Alotaibi, A. Almutairi, and M. M. A. Salama, "An Approach for Managing DG Investment Proposals Considering System Constraints and DG Incentives," Can. Conf. Electr. Comput. Eng., vol. 2018-May, pp. 1-4, 2018.

[9] R. H. A. Zubo, G. Mokryani, H. S. Rajamani, J. Aghaei, T. Niknam, and P. Pillai, “Operation and planning of distribution networks with integration of renewable distributed generators considering uncertainties: A review," Renew. Sustain. Energy Rev., vol. 72, no. October 2016, pp. 1177-1198, 2017.

[10] K. Mahmoud and N. Yorino, "Optimal combination of DG technologies in distribution systems," AsiaPacific Power Energy Eng. Conf. APPEEC, vol. 2016-January, 2016.

[11] S. Satsangi and G. B. Kumbhar, "Analysis of substation energy using conservation voltage reduction in distribution system,” Int. Conf. Electr. Power Energy Syst. ICEPES 2016, pp. 188-193, 2017.

[12] J. A. Duffie, W. A. Beckman, and N. Blair, Solar Engineering of Thermal Processes, Photovoltaics and Wind: John Wiley \& Sons, 2020.. 